\title{
Brief Contents
}

Preface

1 Introduction

2 Basic Physical Concepts

3 Basic Chemical Concepts

4 Properties of Water

5 Atmospheric History and Composition

6 Energy Budget of the Atmosphere

7 Vertical Structure of the Atmosphere

8 Horizontal Motion of the Atmosphere

9 Dynamics of the Ocean

10 Climate through the Ages

11 The Carbon Cycle

12 Cycles of Nitrogen, Phosphorus, and Sulfur

13 Stratospheric Ozone (I): Chapman's Formulation for the Chemistry of an Oxygen-Nitrogen Atmosphere

14 Stratospheric Ozone (II): The Role of Radicals

15 Stratospheric Ozone (III): Influence of Heterogeneous Chemistry

16 Stratospheric Ozone (IV): Influence of Dynamics

17 The Chemistry of the Troposphere

18 The Chemistry of Precipitation

19 Prospects for Climate Change

20 Policy Responses to Climate Change

Notes

References

Appendix

Index 
